\title{
Atividade da enzima nitrato redutase em milho cultivado sob diferentes níveis de adubação nitrogenada e potássica
}

\author{
Activity of the enzyme reductase nitrate in corn cultivated under different levels of nitrogen \\ and potassium fertilization
}

\section{Sueli Maria da Silva ${ }^{\mathrm{I}}$ Lucielle Januário Oliveira ${ }^{\mathrm{I}}$ Francys Pimenta Faria $^{\mathrm{I}}$ Edésio Fialho dos Reis ${ }^{\mathrm{I}}$ Marco Aurelio Carbone Carneiro ${ }^{\mathrm{I}}$ Samuel Mariano da Silva}

\section{RESUMO}

Em função de seu uso na alimentação humana e animal e de um elevado potencial produtivo, o milho constituise num dos mais importantes cereais cultivados $e$ comercializados no mundo. O objetivo deste trabalho foi avaliar o efeito de diferentes doses de nitrogênio e potássio na atividade da enzima redutase do nitrato na cultura do milho em casa de vegetação. Foram utilizadas cinco doses de nitrogênio $\left(0 ; 50 ; 100 ; 150\right.$ e $\left.200 \mathrm{~kg} \mathrm{ha}^{-1}\right)$ e cinco doses de potássio $\left(0 ; 40 ; 80 ; 120\right.$ e $\left.160 \mathrm{~kg} \mathrm{ha}^{-1}\right)$. A atividade da enzima foi estimada in vivo após as plantas atingirem quatro folhas totalmente desdobradas. Utilizou-se o método baseado no princípio de que a quantidade de nitrito liberada por fragmentos de tecidos vivos num tampão, na presença de uma agente permanente e do substrato, reflete a atividade potencial da enzima. A atividade da enzima nitrato redutase sofreu influência significativa da interação das doses de nitrogênio $e$ potássio, já que a interação $N=100 \mathrm{~kg} \mathrm{ha}^{-1}$ e $\mathrm{K}=40 \mathrm{~kg} \mathrm{ha}^{-1}$ proporcionou as melhores médias do experimento. A partir dessa dose, o aumento no fornecimento tanto de nitrogênio quanto de potássio promoveu redução da atividade enzimática.

Palavras-chave: Zea mays L., adubação, enzima redutase do nitrato.

\section{ABSTRACT}

Because of the use in human feeding, animal, and high productive potential, corn is considered to be one of the most important cultivated and commercialized cereals in the world. The aim of this research was to evaluate the effect of different potassium doses and nitrogen in the activity of the enzyme nitrate reductase in the corn culture in a greenhouse environment. Five dosages of nitrogen $(0 ; 50 ; 100 ; 150$ and $\left.200 \mathrm{~kg} \mathrm{~h}^{-1}\right)$ and five potassium dosages $(0 ; 40 ; 80 ; 120$ and $\left.160 \mathrm{~kg} \mathrm{ha}^{-1}\right)$ were used. The activity of the nitrate reductase was esteemed, in vivo after the plants reached four leaves totally unfolded. The method that was used is based on the principle of the amount of nitrite liberated by fragments of alive tissue in a buffer in the presence of a permanent agent and substrate, reflects the potential in situ activity of the enzyme nitrate reductase. The activity of the enzyme nitrate reductase suffered significant influence of the $f$ nitrogen and potassium dosage interaction, where the interaction $N=100 \mathrm{~kg} \mathrm{ha}^{-1}$ and $K=40 \mathrm{~kg}$ $h a^{-1}$ provided the best medium of the experiment. From this dosage on, the increase of nitrogen and potassium supplement caused a reduction of the enzymatic activity.

Key words: Zea mays $L$, fertilization, enzyme redutase of the nitrate.

\section{INTRODUÇÃO}

O milho é o principal cereal produzido no Brasil, cultivado em cerca de 12 milhões de hectares, com produção de aproximadamente 56 milhões de toneladas de grãos e produtividade média de 4,23 toneladas por hectare (CONAB, 2010). Apesar do seu alto potencial produtivo, o que se observa na prática é que sua produção é muito baixa e irregular.

Para obtenção de altas produtividades, é de fundamental importância o suprimento de nutrientes e a adequada proporção entre eles. A disponibilidade do nitrogênio é um dos fatores mais importantes no processo de crescimento e desenvolvimento das plantas (MALAVOLTA, 2006), despenhando para o milho papel importante no acúmulo de proteínas e produtividade dos grãos (PAVINATO et al., 2008). No

'Programa de Pós-graduação em Agrononia, Campus Jataí, Universidade Federal de Goiás (UFG), CP 03, 758000-000, Jataí, GO, Brasil. Email: s_m_s2_4@yahoo.com.br. *Autor para correspondência. 
metabolismo das plantas, participa como constituinte de proteínas, coenzimas, ácidos nucléicos, citrocromo, clorofila, pigmentos e produtos secundários (FERREIRA, et al., 2007). Na planta, quase todo o nitrogênio se encontra em formas orgânicas representadas em maior proporção por aminoácidos e proteínas. Consequentemente, esse elemento é indispensável para a produção de cereais de alta qualidade (MALAVOLTA et al., 1997).

Após o nitrogênio, o potássio é o nutriente absorvido em maior quantidade pelas plantas. Este nutriente tem grande impacto na qualidade da cultura do milho, exercendo influência positiva sobre o peso individual dos grãos e no número de grãos por espiga. Apesar de não fazer parte de nenhum composto dentro da planta, é muito importante em inúmeros processos bioquímicos (MENGEL\& KIRKBY, 2001).

A enzima nitrato redutase atua no primeiro passo da redução do nitrogênio nítrico por plantas superiores. A maior parte do nitrogênio é absorvida pelas plantas na forma de nitrato, que, ao ser absorvido pelas raízes, pode ser reduzido ou armazenado nos vacúolos, ou translocado para a parte aérea, onde será reduzido ou armazenado nos vacúolos foliares (TAIZ \& ZEIGER, 2004). A redução de nitrato ocorre no citossol e envolve a ação da enzima nitrato redutase (NR), produzindo nitrito, o qual adentra aos plastídeos nas raízes ou cloroplastos em folhas, sendo reduzido à amônia por ação da enzima nitrito redutase (NiR), a qual é fixada via glutamato sintase / glutamina sintase (GS/GOGAT) nos aminoácidos, glutamina e glutamato que por sua vez servem de substrato para reações de transaminação, para a produção de aminoácidos necessários à síntese de proteínas (DONATO et al., 2004).

A via de assimilação do nitrato é um processo biológico essencial, por ser a principal rota pela qual o nitrogênio inorgânico é incorporado em compostos orgânicos (FALCÃO, 2006). Portanto, a atuação da enzima nitrato redutase é de fundamental importância na incorporação de nitrogênio inorgânico em moléculas orgânicas complexas, sendo a etapa limitante nesse processo.

O nitrogênio e o potássio estão relacionados pela função do potássio na ativação da enzima redutase do nitrato. VENKAJESAN \& GANAPATHY (2004) relatam uma correlação positiva entre a atividade da enzima redutase do nitrato e a fertilização potássica.

O objetivo deste trabalho foi avaliar o efeito de doses de nitrogênio e potássio na atividade da enzima redutase do nitrato na cultura de milho em casa de vegetação.

\section{MATERIAL E MÉTODOS}

Este estudo foi desenvolvido em casa de vegetação, utilizando-se o delineamento experimental na forma de blocos casualizados, constando de um esquema em fatorial $5 \times 5$, sendo cinco doses de nitrogênio $\left(0 ; 50 ; 100 ; 150\right.$ e $\left.200 \mathrm{~kg} \mathrm{ha}^{-1}\right)$ e cinco doses de potássio $\left(0 ; 40 ; 80 ; 120\right.$ e $\left.160 \mathrm{~kg} \mathrm{ha}^{-1}\right)$ com seis repetições.

O solo utilizado no estudo foi classificado como Latossolo Vermelho distroférrico (EMBRAPA, 1999) coletado em um corte no perfil, apresentando as seguintes características químicas e físicas: $\mathrm{pH}$ em água: 5,$18 ; \mathrm{H}+\mathrm{Al}: 3,13 ; \mathrm{Al}: 0,05 \mathrm{cmol}_{\mathrm{c}} \mathrm{dm}^{-3} ; \mathrm{Ca}: 0,34 \mathrm{cmol}_{\mathrm{c}}$ $\mathrm{dm}^{-3} ; \mathrm{Mg}: 0,32 \mathrm{cmol}_{\mathrm{c}} \mathrm{dm}^{-3} ; \mathrm{K}: 31,00 \mathrm{mg} \mathrm{dm}^{-3} ; \mathrm{P}: 0,72 \mathrm{mg}$ $\mathrm{dm}^{-3}$; matéria orgânica: $14,23 \mathrm{~g} \mathrm{~kg}^{-1}$; argila: $386 \mathrm{~g} \mathrm{~kg}^{-1}$; silte: $421 \mathrm{~g} \mathrm{~kg}^{-1} \mathrm{e}$ areia: $139 \mathrm{~g} \mathrm{~kg}^{-1}$. Após ser peneirado, $\mathrm{o}$ solo coletado foi seco e homogeneizado, recebendo calagem com calcário filler na proporção de $800 \mathrm{mg} \mathrm{kg}^{-1}$ de solo seco para correção e elevação da saturação de bases para $60 \%$, conforme recomendação de SOUSA \& LOBATO (2004), sendo acondicionado em vasos com capacidade de $5,0 \mathrm{~kg}$, os quais receberam adubação mineral com fósforo e micronutrientes.

Um dia antes da semeadura, os nutrientes nitrogênio, na forma de uréia, e potássio, na forma de cloreto de potássio, foram aplicados em solução $(10 \mathrm{~mL}$ vaso $^{-1}$ ) em concentrações de acordo com cada tratamento. A atividade da enzima foi calculada pela quantidade de nitrito liberado pelos tecidos vegetais na solução de incubação, sendo expressa em $\mu$ moles $\mathrm{NO}_{2}^{-h^{-1}} \mathrm{gmf}^{-1}$.

Após as plantas de milho terem atingido o estádio de desenvolvimento $\mathrm{V}_{4}$, foi realizado o corte da segunda folha após a folha encartuchada. A atividade da enzima nitrato redutase foi estimada, in vivo, utilizando-se o método descrito por RADIN (1973), que se baseia no princípio de que a quantidade de nitrito liberada por fragmentos de tecidos vivos num tampão na presença de uma agente permanente e do substrato reflete a atividade potencial da enzima nitrato redutase in situ.

No laboratório, as folhas foram cortadas de modo a obter $0,2 \mathrm{~g}$ de amostra, sendo incubadas em frasco de vidro contendo em $5 \mathrm{~mL}$ de solução tampão fosfato de potássio $\left(\mathrm{K}_{2} \mathrm{HPO}_{4}+\mathrm{KH}_{2} \mathrm{PO}_{4} 0,1 \mathrm{M}\right)$ nitrato de potássio $\left(\mathrm{KNO}_{3} 0,25 \mathrm{M}\right)$ e n-propanol $(1 \% \mathrm{v} / \mathrm{v}), \mathrm{pH}$ 7,0 , submetidos a vácuo durante dois minutos por duas vezes consecutivas e posterior transferência para a incubadora a $33^{\circ} \mathrm{C}$ em ausência de luz. Decorridos 60 minutos, foram retiradas alíquotas de $1,0 \mathrm{~mL}$ do meio de reação, as quais foram transferidas para tubos de ensaio contendo $1,0 \mathrm{~mL}$ de n-naftiletileno diamino bicloridrato 
$0,01 \%(\mathrm{~m} / \mathrm{v})$ e $1,0 \mathrm{~mL}$ de sulfanilamida $0,1 \%$ em ácido clorídrico $3,0 \mathrm{~N}$, para a determinação colorimétrica do nitrito. As leituras foram realizadas em espectrofotômetro a $540 \mathrm{~nm}$, sendo a quantidade de nitrito calculada utilizando-se reta padrão de nitrito de sódio.

Os resultados obtidos foram submetidos à análise de variância pelo programa SAEG 9.1 (SAEG, 2007), sendo efetuado estudo de regressão para os fatores com significância a 5\% de probabilidade de erro.

\section{RESULTADOS E DISCUSSÃO}

A análise de variância revelou que a atividade da enzima nitrato redutase sofreu influência apenas da interação das doses de nitrogênio e potássio, não apresentando influência na presença do nitrogênio ou do potássio separadamente (Tabela 1).

Vários autores relatam os efeitos benéficos da interação nitrogênio x potássio (RUAN, 1999; VENKAJESAN \& GANAPATH, 2004), os quais proporcionam aumentos significativos na produtividade das culturas.

Esse comportamento também pode ser observado na atividade da enzima nitrato redutase, já que a interação N $=100 \mathrm{~kg} \mathrm{ha}^{-1} \mathrm{x} \mathrm{K}=40 \mathrm{~kg} \mathrm{ha}^{-1}$ (Figura 1) e $\mathrm{N}=200 \mathrm{~kg} \mathrm{ha}^{-1} \mathrm{x} \mathrm{K}=160 \mathrm{~kg} \mathrm{ha}^{-1}$ (Figura 2) proporcionou resultados significativamente superiores.

Segundo COSTA et al. (2008), a adubação nitrogenada tem, por muitas vezes, apresentado respostas produtivas abaixo das esperadas, em virtude de inadequados níveis de potássio, o que sugere uma relação entre a absorção e o aproveitamento desses dois macronutrientes.

$\mathrm{Na}$ dose de $40 \mathrm{~kg} \mathrm{ha}^{-1}$ de potássio, à medida que se elevaram os teores de nitrogênio, a atividade da enzima redutase do nitrato apresentou uma variação de 8,2 a 14,82 $\mu$ moles $\mathrm{NO}_{2}{ }^{-} \mathrm{h}^{-1} \mathrm{gmf}^{-1}$ da menor dose até a dose ótima (100kg ha-1), o que representa um aumento de $80 \%$ na atividade enzimática em virtude dos incrementos da adubação nitrogenada (Figura 1).

Tabela 1 - Análise de variância da atividade da enzima nitrato redutase em milho cultivado sob diferentes níveis de nitrogênio e potássio.

\begin{tabular}{llcll}
\hline Fonte & G.L. & SQ & \multicolumn{1}{c}{ QM } & F \\
\hline $\mathrm{N}$ & 4 & 243,396 & 60,8490 & 4,749 \\
$\mathrm{~K}$ & 4 & 14,8222 & 3,7055 & 0,289 \\
Bloco & 5 & 75,3414 & 15,0682 & 1,176 \\
N x K & 16 & 737,277 & 46,0798 & $3,597^{*}$ \\
Resíduo & 51 & 653,406 & 12,8118 & \\
\hline
\end{tabular}

*significativo a $5 \%$ pelo teste $\mathrm{F}$
Isso sugere que a enzima possa ter sido ativada pelo substrato, uma vez que é considerada como sendo um dos melhores exemplos de enzima induzida pelo substrato em plantas superiores (CAMARGOS, 2007).

A partir da dose de $100 \mathrm{~kg} \mathrm{ha}^{-1}$, o aumento no fornecimento de nitrogênio promoveu uma redução da atividade da enzima. Provavelmente, tal comportamento deva-se ao fato de que, nas doses mais altas de nitrogênio, a atividade enzimática tenha sido limitada pela diminuição na absorção de micronutrientes.

De acordo com FANCELLI \& TSUMANUMA (2007), doses elevadas de nitrogênio no sulco da semeadura podem favorecer a acidificação ou alcalinização da rizosfera em função da fonte empregada, afetando o desempenho das raízes, a vida no solo e a taxa de absorção de micronutrientes.

Neste experimento, a fonte de nitrogênio empregada foi uréia, a qual pode ter causado a acidificação da rizosfera. Segundo VIANA (2010), com a diminuição do $\mathrm{pH}$, o molibdênio torna-se indisponível para a planta e, em casos de deficiência desse nutriente, a atividade da nitrato redutase em plantas não leguminosas é reduzida em cerca de $26 \%$. Apesar da pequena quantidade absorvida pela planta, o molibdênio exerce papel indispensável na assimilação do nitrato, atuando diretamente em nível da nitrato redutase.

Na dosagem de $100 \mathrm{~kg}$ de nitrogênio ha ${ }^{-1}$, foi possível observar que o potássio contribui com $10 \%$ de aumento na atividade enzimática da dose zero para dose de $40 \mathrm{~kg} \mathrm{ha}^{-1}$ (Figura 3). Esse fato pode indicar que o potássio potencializa a atividade enzimática. Em todos os tratamentos, foi observado comportamento semelhante, evidenciando a participação do potássio na atividade enzima nitrato redutase em plantas jovens de milho.

Esta influência do potássio sobre a nitrato redutase pode ser associada ao fato do potássio participar da regulação da absorção do nitrato pelas raízes das plantas. De acordo com KRAUSS (2005), quando o nitrato é reduzido nas folhas, forma-se malato em resposta ao aumento do $\mathrm{pH}$ interno do tecido. Segundo o autor, parte do malato é transferido ao floema e acompanhado pelo potássio para ser translocado para as raízes, local onde sofre a descarboxilação. O ácido carbônico produzido é liberado no meio em troca do nitrato absorvido, assim controlando a absorção do nitrato. O potássio recirculado serve como contra-íon para o transporte de nitrato no xilema até a parte aérea (MENGEL\& KIRKBY, 2001).

Plantas com inadequado suprimento de potássio reduzem a eficiência do transporte de nitrato 


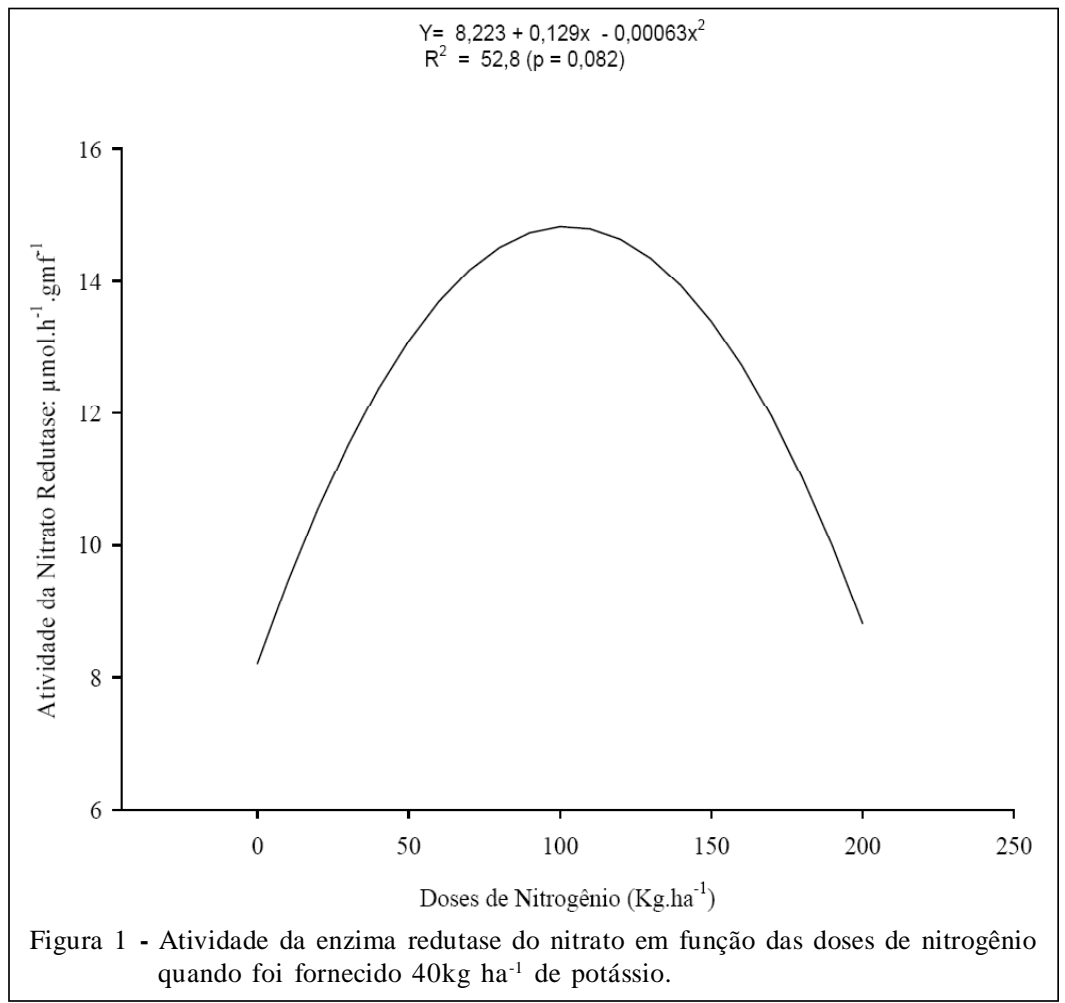

para a parte aérea. Isso induz a redução do nitrato e acumulação de aminoácidos nas raízes, qualquer sinal de excesso de nitrato induz uma resposta negativa nas raízes para cessar a absorção de nitrato, embora o nitrato possa estar presente na rizosfera da planta (KRAUSS, 2005), de forma que a quantidade de nitrato, substrato da enzima nitrato redutase, no citoplasma é diminuída. MARSCHNER (1995) relata a alta probabilidade da participação do potássio na ativação nitrato redutase.

Em contra partida, como pode ser verificado na figura 2 , o excesso de potássio $\left(160 \mathrm{~kg} \mathrm{ha}^{-1}\right)$ nos diversos níveis de nitrogênio resultou em redução da

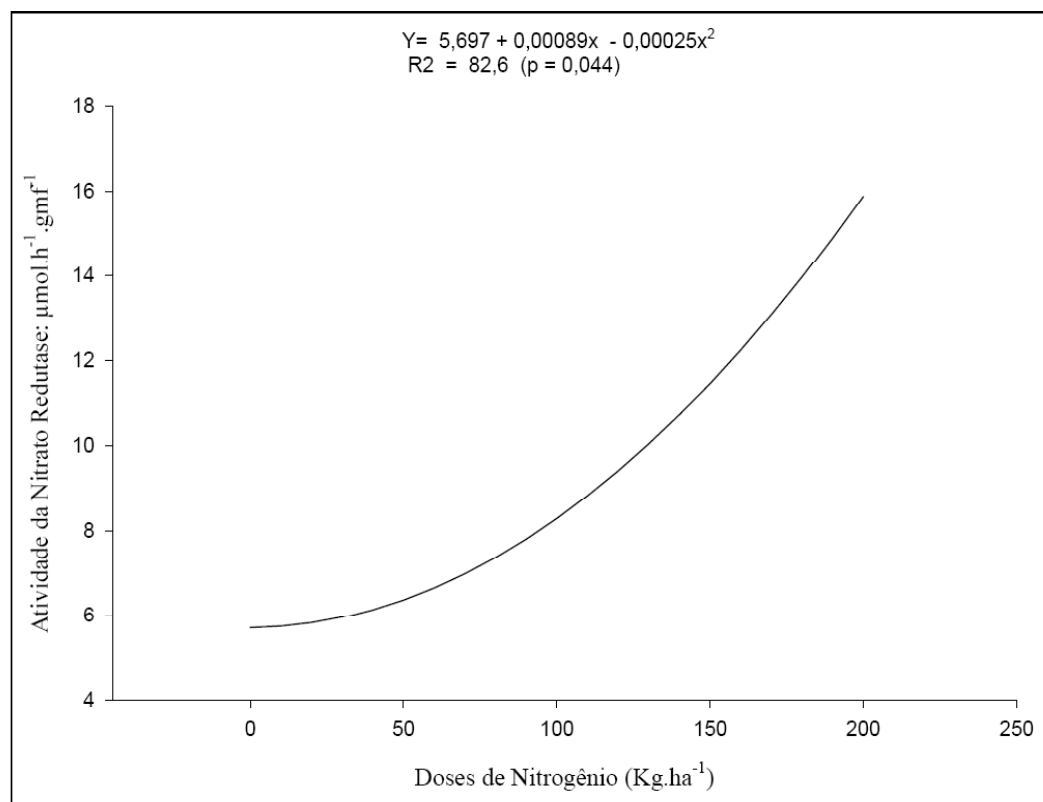

Figura 2 - Atividade da enzima redutase do nitrato em função das doses de nitrogênio quando foi fornecido $160 \mathrm{~kg} \mathrm{ha}^{-1}$ de potássio.

Ciência Rural, v.41, n.11, nov, 2011. 


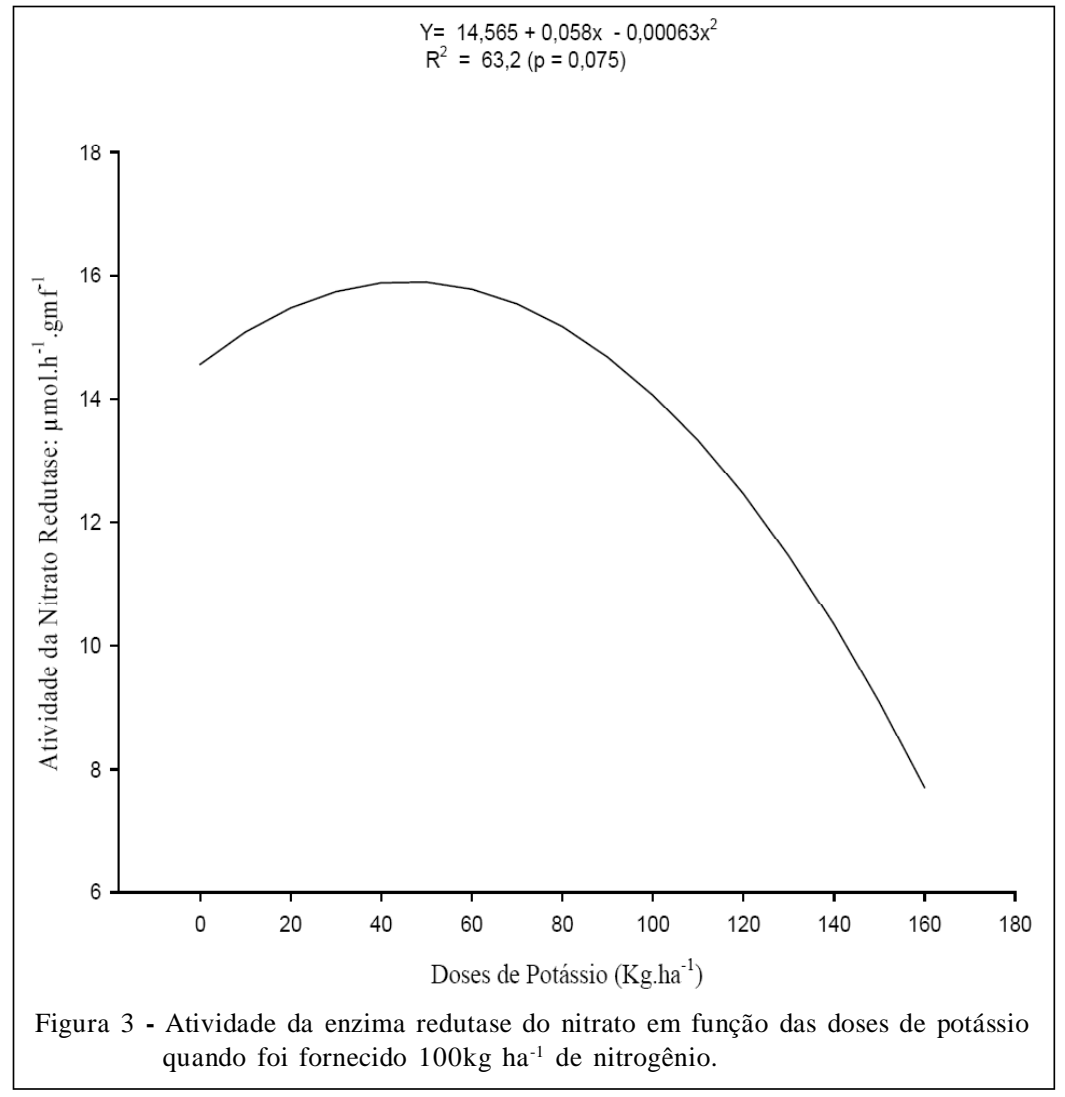

atividade enzimática, não ultrapassando a 10,0 $\mu$ moles $\mathrm{NO}_{2}^{-} \mathrm{h}^{-1} \mathrm{gmf}^{-1}$.

Segundo STROMBERGER et al. (1994), nas plantas de milho, o potássio participa em inúmeros processos que envolvem o metabolismo do nitrogênio na planta, no entanto, o excesso de potássio restringe a absorção de nitrogênio.

Nesse caso, a atividade enzimática pode ter sido afetada pelo efeito salino, devido ao excesso no fornecimento do cloreto de potássio. Considerada uma espécie moderadamente sensível à salinidade, com o aumento da concentração de sais no meio radicular, o milho sofre redução progressiva do crescimento (FERREIRA et al., 2007). Vários trabalhos reportam os efeitos deletérios do estresse salino sobre o crescimento do milho, independentemente da variável utilizada para esta avaliação (IZZO et al., 1991; HASANEEN et al., 1994; SANEOKA et al., 1995).

Segundo SAGI \& LIPS (1998), a enzima nitrato redutase tem sua síntese afetada por variações no suprimento de nitrogênio e pela salinidade do solo. Uma das explicações mais aceita para a inibição do crescimento pela condição salina do solo é o desvio de energia do crescimento para a manutenção, isto é, a redução na matéria seca pode refletir o custo metabólico de energia, associado à adaptação a salinidade e redução no ganho de carbono (VIEGAS, 2004). Provavelmente, o gasto de energia para adaptação da planta à salinidade pode ter interferido na atividade da enzima nitrato redutase, uma vez que essa enzima utiliza energia advinda da fotossíntese.

ARAGÃO et al. (2010), trabalhando com a assimilação do nitrato em feijão-caupi submetido à salinidade, observaram que o estresse salino provocou a redução na atividade da enzima nitrato redutase. Esse fato tem sido associado a um efeito direto da redução do potencial de água do tecido, provocado pela salinidade sobre a atividade ou pela indução da síntese da redutase do nitrato (RAO \& GNANAM, 1990).

A combinação das doses de $160 \mathrm{~kg} \mathrm{ha}^{-1}$ potássio e $200 \mathrm{~kg} \mathrm{ha}^{-1}$ de nitrogênio produziu um efeito bastante diferente na atividade enzimática. A dose de $160 \mathrm{~kg} \mathrm{ha}^{-1}$ de potássio, combinada com as diferentes doses de nitrogênio, apresenta resultados inferiores a $11,45 \mu$ moles $\mathrm{NO}_{2}^{-} \mathrm{h}^{-1} \mathrm{gmf}^{-1}$ na atividade da enzima. No entanto, quando essa dose foi combinada com a maior dose de nitrogênio, a atividade enzimática atingiu valores de até $15,87 \mu$ moles $\mathrm{NO}_{2}^{-} \mathrm{h}^{-1} \mathrm{gmf}^{-1}$, o que não encontra explicação na literatura. 


\section{CONCLUSÃO}

A atividade enzimática respondeu significativamente à interação nitrogênio x potássio. A interação $\mathrm{N}=100 \mathrm{~kg} \mathrm{ha}^{-1} \mathrm{e} \mathrm{K}=40 \mathrm{~kg} \mathrm{ha}^{-1}$ proporcionou os melhores resultados da enzima nitrato redutase, coincidindo com a adubação recomendada para esta região. No entanto, doses de nitrogênio acima de $100 \mathrm{~kg}$ $\mathrm{ha}^{-1}$ e de potássio acima de $40 \mathrm{~kg} \mathrm{ha}^{-1}$ podem causar redução na atividade enzima nitrato redutase.

\section{REFERÊNCIAS}

ARAGÃO, R.M. et al. Absorção, fluxo no xilema e assimilação do nittrato em feijão-caupi submetido à salinidade. Ciência Agronômica, v.41, n.1, p.100-106, 2010. Disponível em: <http://www.ccarevista.ufc.br/seer/index.php/ccarevista/article/ viewFile/664/413>. Acesso em: 05 jan.2011. doi: 10.1590/ S1415-43662002000300008.

CAMARGOS, L.S. Alterações no metabolismo de compostos nitrogenados em calopogonium mucunoides em resposta a diferentes fontes de nitrogênio: efeitos na nodulação e na fixação. 2007. 142f. Tese (Doutorado em Biologia Vegetal) - Curso de Pós-graduação Biologia Vegetal, Universidade Estadual de Campinas, SP.

CONAB - COMPANHIA NACIONAL DE ABASTECIMENTO. Série histórica. Comparativo de área, produção e produtividade. Ministério da Agricultura, Pecuária e Abastecimento. Disponível em: <http://www.conab.gov.br/ conteudos.php $? \mathrm{a}=1252 \& \mathrm{t}=\&$ Pagina_objcmsconteudos $=2 \# \mathrm{~A}$ objcmsconteudos>. Online. Acesso em: 15 maio, 2011.

COSTA, K.A.P. et al. Extração de macronutrientes pela fitomassa do capim-xaraés em função de doses de nitrogênio e potássio. Ciência Rural, v.38, n.4, p.1162-1166, 2008. Disponível em: <http://www.scielo.br/scielo.php?pid=S0103$84782008000400043 \&$ script=sci_arttext $>$. Acesso em: 12 abr. 2010. doi: 10.1590/S0103-84782008000400042.

DONATO, V.M.T.S. et al. Atividade enzimática em variedades de cana-de-açúcar cultivadas in vitro sob diferentes níveis de nitrogênio. Pesquisa Agropecuária Brasileira, v.39, n.11, p.1087-1093, 2004. Disponível em: <http://www.scielo.br/pdf/ pab/v39n11/22580.pdf >. Acesso em: 21 ago. 2009. doi: 10.1590/S0100-204X2004001100006.

EMBRAPA. Sistema Brasileiro de Classificação de Solos. Brasília: EMBRAPA/CNPS, Rio de Janeiro, 1999. 412p.

FANCELLI, A.L.; TSUMANUMA, G.M. Nitrogênio e enxofre nas culturas de milho e feijão. In: YAMADA, T. et al. Nitrogênio e enxofre na agricultura Brasileira. Piracicaba: IPNI, 2007. Cap.13, p.445-482.

FALCÃO,V.R. Aspectos moleculares de nitrato redutase da macroalga marinha Gracilaria tenuistipitata (RHODOPHYTA): seqüenciamento do gene e estudo da expressão do RNA mensageiro. 2006. 132f. Tese (Doutorado em Química) - Curso de Pós-graduação em Química, Universidade de São Paulo, SP.
GARCIA, G. O. et al. Teores foliares dos macronutrientes catiônicos e suas relações com sódio em plantas de milho sob estresse salino. Idesia, v.25, n.3, p.93-106, 2007. Disponível em:<http:// www.scielo.cl/scielo.php? script $=$ sci_arttext\&pid $=$ S0718 34292007000300010 >. Acesso em: 16 de jun. 2010. doi: $10.4067 /$ S0718-34292007000300010.

HASANEEN, M.N.A. et al. Growth, carbohydrates and associated invertase and amylase activities in castor bean and maize as affected by metribuzin and $\mathrm{NaCl}$. Biologia Plantarum, v.36, n.3, p.451-459, 1994. Disponível em: <http://www.springerlink.com/content/rx81742206018353/>. Acesso em: 19 de jun. 2010. doi : 10.1007/BF02920948.

IZZO, R. et al. Growth and mineral absorption in maize seedlings as affected by increasing $\mathrm{NaCl}$ concentrations. Journal of Plant Nutrition, v.14, n.7, p.687-699, 1991. Disponível em: <http://www.tandfonline.com/doi/abs/10.1080/ 01904169109364235\#preview>. Acesso em: 05 fev. 2010. doi: 10.1080/01904169109364235.

KRAUSS A. Potassium effects on yield quality. In: YAMADA, T.; ROBERTS, T.L. Potássio na agricultura brasileira. Piracicaba: IPNI, 2005. Cap. 11, p.239-256.

MALAVOLTA, E. et al. Avaliação do estado nutricional das plantas: princípios e aplicações. Piracicaba: POTAFOS, 1997. 319p.

MALAVOLTA, E. Manual de nutrição mineral de plantas. São Paulo, Agronômica Ceres, 2006. 638p.

MARSCHNER, H. Mineral nutrition of higher plants. London: Academic, 1995. 889p.

RADIN, J.W. In vivo assay of nitrate reductase in cotton leaf discs. Plant Physiology v.51, n.2, p.332-336, 1973. Disponível em: <http://www.plantphysiol.org/content/51/2/ 332.full.pdf+html>. Acesso em: 14 jun. 2010. doi:10.1104/ pp.51.2.332 .

MENGEL, K.; KIRKBY, E.A. Principles of plant nutrition. London: Kluwer Academic, 2001. 849p.

PAVINATO, P.S. et al. Nitrogênio e potássio em milho irrigado: análise técnica e econômica da fertilização. Ciência Rural, v.38, n.2, p.358-364, 2008. Disponível em: <http:// www.scielo.br/pdf/cr/v38n2/a10v38n2.pdf $>$. Acesso em: 15 ago. 2010. doi 10.1590/S0103-84782008000200009.

RAO, K.R.; GNANAM, A. Inhibition of nitrate and nitrite reductase activity by salinity stress in Sorghum vulgare. Phytochemistry, v.29, n.4, p.1047-1049, 1990. Disponível em: <http:// www.sciencedirect.com/science/article/pii/003194229085400A>. Acesso em: 18 ago. 2010. doi:10.1016/0031-9422(90)85400-A.

RUAN, J. et al. Effects of potassium and magnesium nutrition on the quality components of differents types of tea. Journal of Science of Food and Agriculture, v.79, n.1, p.47-52, 1999. Disponível em: <http://onlinelibrary.wiley.com/doi/10.1002/\%28SICI\%2910970010\%28199901\%2979:1\%3C47::AID-JSFA172\%3E3.0.CO;2-A/ abstract>. Acesso em: 17 set. 2009. doi:10.1002/(SICI)10970010(199901)79:1<4JSFA172>3.0.CO;2-A.

SAEG. Sistema para Análises Estatísticas. Versão 9.1. Viçosa: Fundação Arthur Bernardes - UFV, 2007. On-line. Disponível em: <http://www.ufv.br/saeg/>. Acesso em: 18 ago. 2009. 
SAGI, M.; LIPS, H.S. The levels of nitrate reductase and MoCo in annual ryegrass as affected by nitrate and ammonium nutrition. Plant Science, v.135, n.1, p.17-24, 1998. Disponível em: <http://www.sciencedirect.com/science/article/ pii/S0168945298000843> Acesso em : 16 de jul. 2010. doi :10.1016/S0168-9452(98)00084-3.

SANEOKA, H. et al. Salt tolerance of glycinebetaine-deficient and-containing maize lines. Plant Physiology, v.107, n.2, p.631-638, 1995. Disponível em: <http://www.ncbi.nlm.nih.gov/ pmc/articles/PMC157167/pdf/1070631.pdf $>$. Acesso em: 15 out. 2009. doi:10.1104/pp.107.2.631.

SOUSA, D.M.G.; LOBATO, E. Adubação com nitrogênio. In: SOUSA, D.M.G.; LOBATO, E. Cerrado: correção do solo e adubação. Brasília: Embrapa Informação Tecnológica, 2004. 416p.

STROMBERGER, J.A. et al. Interactions of potassium with nitrogen and their influence on growth and yield potential in maize. Journal of Plant Nutrition, v.17, n.1, p.19-37, 1994. Disponível em: <http://cat.inist.fr/ ? aModele $=$ afficheN\&cpsidt $=3894678>$. Acesso em: 18 out. 2009. doi: 10.1080/01904169409364707.
TAIZ, L.; ZEIGER, E. Fisiologia vegetal. Porto Alegre: Artmed, 2004. 719p.

VENKATESAN, S.; GANAPTHY, M. N.K. Nitrate reductase activity in tea as influenced by various levels or nitrogen and potassium fertilizers. Communications in Soil Science and Plant Analysis, v.35, n.9-10, p.1283-1291, 2004. Disponível em: <http://www.tandfonline.com/doi/abs/10.1081/ CSS-120037546>. Acesso em: 16 set. 2009. doi :10.1081/ CSS-120037546.

VIANA, E.M.; KIEHL, J.C. Doses de nitrogênio e potássio no crescimento de trigo. Bragantia, v.69, n.4, p.975-982, 2010. Disponível em: <http://www.scielo.br/scielo.php?pid=S0006$87052010000400024 \&$ script $=$ sci_arttext $>$. Acesso em:13 ago. 2009. doi: $10.1590 / \mathrm{S} 0006-87052010000400024$.

VIÉGAS, R.A. et al. Redução assimilatória de NO - em plantas de cajueiros cultivados em meio salinizado. Revista brasileira de engenharia agrícola e ambiental. v.8, n.2-3, p.189-195, 2004. Disponível em: <http://www.scielo.br/scielo.php?pid=s141543662004000200005\&script=sci_arttext $>$. Acesso em: 14 mar. 2010. doi: 10.1590/S1415-43662004000200005. 